IOS Press

\title{
Management of invasive fungal infections in the pediatric intensive care unit
}

\author{
Kathleen Chiotos ${ }^{\mathrm{a}, \mathrm{b}, *}$, Brian T. Fisher ${ }^{\mathrm{b}, \mathrm{c}, \mathrm{d}, \mathrm{e}}$ and Theoklis Zaoutis $\mathrm{b}, \mathrm{c}, \mathrm{d}, \mathrm{e}, \mathrm{f}$ \\ a Division of Critical Care, The Children's Hospital of Philadelphia, Philadelphia, PA, USA \\ ${ }^{\mathrm{b}}$ Division of Infectious Diseases, The Children's Hospital of Philadelphia, Philadelphia, PA, USA \\ ${ }^{\mathrm{c}}$ Department of Pediatrics, University of Pennsylvania Perelman School of Medicine, Philadelphia, PA, USA \\ ${ }^{\mathrm{d}}$ Center for Clinical Epidemiology and Biostatistics, University of Pennsylvania Perelman School of Medicine, \\ Philadelphia, PA, USA \\ ${ }^{\mathrm{e}}$ Center for Pediatric Clinical Effectiveness, The Children's Hospital of Philadelphia, Philadelphia, PA, USA \\ ${ }^{\mathrm{f}}$ Department of Biostatistics and Epidemiology, University of Pennsylvania Perelman School of Medicine, \\ Philadelphia, PA, USA
}

Received 10 August 2014

Revised 11 October 2014

Accepted 14 November 2014

\begin{abstract}
Invasive candidiasis (IC) are the most common invasive fungal infections in pediatric intensive care unit patients due to commonly present risk factors including central venous catheters, antibiotic exposure, recent surgery, total parenteral nutrition, and prior colonization with Candida species. These infections are economically costly and have been associated with an attributable mortality of approximately $10 \%$. As a result, investigators have attempted to identify cohorts of pediatric intensive care unit patients at highest risk of development of IC who may benefit from prophylactic, early empiric, or pre-emptive therapy. This review article will consider these prediction models and therapeutic approaches. Additionally, the management of confirmed IC, including anti-fungal therapeutic options, evaluation for disseminated disease, and management of central venous catheters, will be reviewed.
\end{abstract}

Keywords: Candida, candidiasis, anti-fungal agent, pediatrics, pediatric intensive care unit

\section{Introduction}

Candida and Aspergillus species represent the most common etiologies of fungal infection in children, with infections caused by other organisms, including Mucorales species, Cryptococcus, and Fusarium reported far less frequently. While infections with these mold organisms are limited to profoundly

\footnotetext{
*Corresponding author: Kathleen Chiotos, MD, Division of Infectious Diseases, Abramson Research Building, Room 1202, The Children's Hospital of Philadelphia, 34th and Civic Center Blvd, Philadelphia, PA 19104, USA. Tel.: +1 215313 9399; Fax: +1 215 5902025; E-mail: chiotosk@email.chop.edu.
}

immunocompromised patients, risk factors for development of candidal infections include a number of factors common to pediatric intensive care unit (PICU) patients such as underlying malignancy, prior antibiotic exposure, presence of invasive devices including central venous catheters (CVC), total parenteral nutrition (TPN), and prior colonization with Candida [1]. Not surprisingly, infections with Candida species are the most common invasive fungal infection (IFI) in the PICU, representing 9-15\% of bloodstream infections (BSI) in this population [2-6]. The focus of this review, therefore, will be on prevention and management of invasive candidal (IC) infections, including candidemia and disseminated candidiasis in the PICU. 


\section{Epidemiology}

The incidence of candidemia increased dramatically between 1979-2000, likely due to increasing numbers of pediatric patients with malignancies, hematopoietic stem cell transplantation (HSCT), use of invasive devices such as central lines and mechanical ventilation, and extreme prematurity [7, 8]. Since the early part of the 21st century, however, the incidence of candidemia in pediatrics has seemed to level off or decline [7, 9-13]. Proposed hypotheses to explain this observed decrease include use of fluconazole prophylaxis in at risk neonates and infants, improved antibiotic utilization, and improved infection control practices for management of CVC's [4, 11-16]. The full explanation for this decreased incidence is likely a combination of these factors.

Overall, Candida species account for $10 \%$ of BSI in hospitalized children in the US with almost two-thirds of these infections acquired nosocomially [17-20]. The epidemiology of candidal infections specifically in the PICU is less well described, but available data suggests that Candida species are common etiologies of severe sepsis and cause $9-15 \%$ of BSI in the PICU population [2-6, 21]. In a small series of patients with candidemia, $27 \%$ of patients developed severe sepsis [4]. The crude mortality rate in pediatric patients with candidemia is between $15-25 \%$ with attributable mortality of approximately $10 \%$, but this can approach 50\% among PICU patients with severe sepsis [19, 22-27]. Candidemia is associated with a 21-day increase length of stay and increased total charges of $\$ 92,266$ [22].

Candida albicans remains the most common species among hospitalized children with candidemia, accounting for $40-50 \%$ of isolates, though in some series, non-albicans Candida species collectively exceed the rates of $C$. albicans. Of the non-albicans Candida species, Candida parapsilosis and Candida glabrata are the most common accounting for between $15-30 \%$ and $10-26 \%$ of isolates, respectively $[4,9,19$, 24, 27-31]. Interestingly, the epidemiology of Candida species may differ slightly among PICU populations in different regions. In a recent European report limited to only PICU patients, $C$. albicans represented approximately $38 \%$ of isolates, followed by $C$. parapsilosis (30\%), C. tropicalis (15\%) and C. glabrata (3\%) [32]. Explanations for the increasing frequency of nonalbicans Candida species include widespread azole use for antifungal prophylaxis or treatment as well as increasing use of CVC's, particularly in cases of $C$. parapsilosis, which has a tendency to adhere to foreign material [32]. Understanding the local epidemiology of candidal infections can have significant impact on empiric therapy as unlike C. albicans, C. glabrata is more commonly associated with fluconazole resistance and Candida krusei has intrinsic fluconazole resistance [33].

\section{Diagnosis}

Timely initiation of anti-fungal therapy in patients with invasive candidal infections has been shown to improve outcomes in several retrospective studies, though prompt diagnosis of candidal infections is challenging in practice [34-36]. Clinical diagnosis of invasive candidal infection is impossible due to the lack of specificity of clinical findings such as fever and sepsis syndrome associated with this diagnosis. Standard blood cultures routinely detect Candida species, but at best have a sensitivity of $63-83 \%$ for candidemia and on average take approximately 25 hr to turn positive [37, 38]. This is not improved by sending specific "fungal" blood cultures. Nonculture based methods, including $(1 \rightarrow 3) \beta$-D-glucan and mannan antigen/antibody ( $\mathrm{Ag} / \mathrm{Ab})$ assays have shown promise in adult patients in rapidly detecting invasive candidal infections, but little pediatric data exists on $(1 \rightarrow 3) \beta$-D-glucan and no pediatric data exists on mannan $\mathrm{Ag} / \mathrm{Ab}$ assays [39-47]. Use of these assays in pediatric patients is not currently recommended [48-50]. In immunocompromised patients, evaluation of parencyhmal sites of candidal infection could include ultra-sound, computerized tomography and magnetic resonance imaging. Using these imaging modalities to better evaluate the brain, lungs, bone and/or abdominal viscera can be especially helpful when disseminated candidiasis is suspected even in the absence of a positive blood culture.

\section{Risk factors}

Limitations of diagnostics coupled with significant risk of mortality, higher cost, and longer duration of hospital stay associated with invasive candidal infections has led investigators to attempt to identify factors associated with invasive candidal infection in intensive care unit (ICU) patients. A number of risk factors have been reported among both adult and 
Table 1

Risk factors associated with invasive candidiasis

\begin{tabular}{ll}
\hline $\begin{array}{l}\text { Pediatric and adult } \\
\text { risk factors for } \\
\text { invasive candidiasis }\end{array}$ & References \\
\hline $\begin{array}{l}\text { Intensive care unit stay } \\
\text { Presence of a central } \\
\text { venous catheter }\end{array}$ & $31,61,62^{\mathrm{a}}$ \\
Total parenteral nutrition & $31,51^{\mathrm{b}}, 53,56,61,62^{\mathrm{a}}$ \\
$\quad$ administration & $21,31,53,56,61,62^{\mathrm{a}}$ \\
Prior Candida species & $57,58,59,60$ \\
$\quad$ colonization & $31,53,55$ \\
Mechanical ventilation & $51^{\mathrm{b}}, 53$ \\
Broad spectrum & \\
$\quad$ antibiotic exposure & $61,62^{\mathrm{a}}, 93$ \\
Recent surgery & $61,62^{\mathrm{a}}$ \\
Dialysis & $51^{\mathrm{b}}$ \\
Malignancy & $52,61,62^{\mathrm{b}}$ \\
Immunosuppressive & \\
medications & \\
\hline
\end{tabular}

${ }^{a}$ Prediction rule from Ostroski-Zeichner et al. [61, 62]: Intensive care unit $>4$ days, and central venous catheter, and mechanically ventilated for $>48 \mathrm{hr}$, and broad spectrum antibiotic use, and at least one of the following: any surgery, immunosuppressive use, pancreatitis, total parenteral nutrition, dialysis, or steroid use. ${ }^{b}$ Prediction rule from Zaoutis et al. [51]: pediatric intensive care unit patients with central venous catheter, malignancy, total parenteral nutrition, $>3$ days of vancomycin or anti-anaerobic drug exposure within $2 \mathrm{wk}$; combinations of the identified risk factors increases predicted probability of invasive candidiasis up to $46 \%$.

pediatric patients (Table 1). These risk factors include ICU stay, presence of a CVC, TPN administration, prolonged exposure to antimicrobial agents, recent surgery, dialysis, immunocompromised status, prior Candida species colonization, and mechanical ventilation [1, 31, 51-57]. While it is important to understand risk factors for IC, the aforementioned risk factors are individually of limited use to risk stratify patients in the PICU given the frequency with which they are each encountered.

Several investigators, therefore, have developed prediction models to aid clinicians in identifying patients at highest risk for developing IC. Several adult prediction models have been derived and include factors such as candidal colonization, combinations of the above risk factors, or both of these; all are limited by poor positive predictive value but have good negative predictive value [58-63]. Only two pediatric prediction models exist [21, 51]. The first [21] identified hospitalization $>15$ days prior to PICU admission, fever and thrombocytopenia at PICU admission, and TPN as being independently associated with IC. Various scores were assigned to each of these identified risk factors and, at the authors' defined cut-offs, specificity and negative predictive value exceeded $90 \%$. However, positive predictive value and sensitivity were poor, limiting the use of this model in identifying patients who may benefit from prophylaxis or early empiric therapy [21].

A second study [51] identified independent risk factors for development of invasive candidal infection in the PICU in a single center. Using a combination of risk factors they calculated predicted probability of invasive candidal infection. Presence of a central venous catheter, malignancy, receipt of vancomycin $>3$ days in the prior to $2 \mathrm{wk}$, and receipt of agents with anti-anaerobic activity were factors independently associated with invasive candidal infection. Combining these risk factors generated up to a $46 \%$ predicted probability of developing candidemia, suggesting that this may be a cohort of patients who would benefit from either prophylaxis or early empiric antifungal therapy [51]. However, these data have not been validated in other PICU's and local practice patterns and Candida epidemiology may influence its generalizability. Additionally, the inclusion of novel diagnostic modalities such as biomarkers into a prediction model may improve the operating characteristics of this prediction rule and thus aid pediatric intensivists in identifying patients at highest risk of fungal infection.

\section{Prophylaxis}

If such a prediction model could be developed, targeted prophylaxis, as is done with HSCT patients, patients with high risk leukemias, and sometimes extremely low birth weight infants could be initiated in a subset of high risk PICU patients (Table 2) [49, 64-71]. An expected rate of invasive candidal infection of $10 \%$ has been proposed as a cutoff for which prophylaxis should be given [21, 51, 72].

Though not based on validated prediction models, several adult studies conducted primarily in surgical intensive care units have demonstrated a reduction in invasive candidal infections with fluconazole prophylaxis. These studies have included patients undergoing high risk orthotopic liver transplant, abdominal surgery with bowel perforation or anastomotic leak, heavily colonized patients, and patients with expected lengthy ICU stays or prolonged need for mechanical ventilation [73-81]. Four meta-analyses, which included these trials and others, showed decreased incidence of candidal infections in patients receiving prophylaxis 
Table 2

Summary of recommendations for prophylaxis, empiric therapy, and definitive therapy for invasive candidiasis

\begin{tabular}{|c|c|c|}
\hline Conditions & $\operatorname{Drug}(\mathrm{s})$ of choice & Comments \\
\hline \multicolumn{3}{|l|}{ Prophylaxis } \\
\hline $\begin{array}{l}\text { High risk leukemia or } \\
\text { hematopoietic stem cell } \\
\text { transplantation }\end{array}$ & Fluconazole & $\begin{array}{l}\text { Voriconazole is an alternative when additional anti-mold } \\
\text { prophylaxis desired }\end{array}$ \\
\hline \multicolumn{3}{|l|}{ Empiric therapy } \\
\hline Neutropenic patient & $\begin{array}{l}\text { Echinocandin, liposomal } \\
\text { amphotericin B }\end{array}$ & \\
\hline $\begin{array}{l}\text { Non-neutropenic patient } \\
\text { Definitive therapy }\end{array}$ & No recommendation & When prolonged fever used as criteria, no benefit of prophylaxis \\
\hline $\begin{array}{l}\text { Candidemia - moderate-severe } \\
\text { illness, recent azole } \\
\text { exposure, neutropenia }\end{array}$ & $\begin{array}{l}\text { Echinocandin, liposomal } \\
\text { amphotericin }\end{array}$ & $\begin{array}{l}\text { Therapy continued for } 14 \text { days from first negative culture or central } \\
\text { venous catheter removal; when clinically improved, may } \\
\text { consider step down to fluconazole if isolate susceptible. Any } \\
\text { evidence of disseminated disease would warrant longer therapy. }\end{array}$ \\
\hline $\begin{array}{l}\text { Candidemia - mild illness, no } \\
\text { recent azole exposure, } \\
\text { non-neutropenic }\end{array}$ & Fluconazole & $\begin{array}{l}\text { Therapy continued for } 14 \text { days from first negative culture or central } \\
\text { venous catheter removal. Any evidence of disseminated disease } \\
\text { would warrant longer therapy. }\end{array}$ \\
\hline
\end{tabular}

and two of these meta-analyses showed a reduction in mortality $[73,74,82,83]$. However, these metaanalyses were limited as they combined studies with variable definitions of "high-risk" patients as well as variability in prescribed antifungal agents.

The one pediatric study evaluating prophylactic antifungals in the PICU was a non-randomized retrospective study utilizing historical controls in which enteral amphotericin B was given to all mechanically ventilated patients with an expected PICU stay of $>7$ days. One hundred and eighty five patients met these criteria and they were compared with 196 historical controls; groups were reportedly similar in their identified risk factors, including presence of CVC's, TPN, antibiotic exposure, and duration of PICU stay. The rate of Candida bloodstream infection decreased from $10.7 \%$ to $2.7 \%$ between the two time periods, suggesting that perhaps prophylactic enteral amphotericin B reduces risk of candidemia in this population, though this study is limited in that it is not randomized and only included patients from a single center [84].

Based on aforementioned adult data, the Infectious Diseases Society of America (IDSA) guidelines recommend fluconazole prophylaxis in high-risk adult patients in units with high incidence of IC [50]. The IDSA guideline does not provide specific criteria to define high-risk status nor do they provide any specific recommendation for PICU patients. The most recent adult European Society of Clinical Microbiology and Infectious Diseases (ESCMID) guidelines recommend fluconazole prophylaxis in adult patients who have recently undergone abdominal surgery and have anastomotic leak or perforation; despite the paucity of pediatric data, the ESCMID guidelines suggest that antifungal prophylaxis is "reasonable" in PICU patients, especially those who have recently undergone abdominal surgery $[69,85]$.

Following publication of the IDSA and ESCMID guidelines, a multi-center, randomized, placebo controlled double blind study of caspofungin prophylaxis in adult ICU patients identified as high-risk using a previously derived prediction model was performed $[62,86]$. No significant difference in probable or proven IC, time to IC, mortality, or ICU/hospital length of stay was detected in patients who received caspofungin prophylaxis versus those who received placebo. Notably, this study may have been underpowered given lower than expected incidence of IC in this cohort [86]. Additional adult and pediatric specific studies on the role of prophylaxis in specific PICU populations are needed to better inform future guidelines.

\section{Treatment}

\subsection{Empiric therapy}

Empiric therapy refers to administration of antifungal therapy after observing symptoms or signs of infection that may have a fungal etiology. As noted above this can be challenging as there are limited clinical findings that are specific to invasive candidal infections. The threshold for initiating empiric antifungal therapy is different for neutropenic and 
non-neutropenic ICU patients and thus the two clinical scenarios are discussed separately below $[49,50,85]$.

\subsubsection{Neutropenic patients}

In children with hematologic malignancies or HSCT who experience prolonged neutropenia, initiation of empiric anti-fungal therapy with new or persistent fever despite broad-spectrum antibiotics $>4$ days is recommended in high risk hosts; depending on the report, the definition of prolonged neutropenia varies from greater than 7 days (IDSA guidelines) to greater than 10 days (ESCMID guidelines, European Conference on Infections in Leukaemia (ECIL)-4 guidelines, International Pediatric Fever and Neutropenia Guidelines) and an absolute neutrophil count less than 100 (IDSA guidelines) to less than 500 (ESCMID guidelines, ECIL-4 guidelines) [48-50, 69, 87]. Based on pediatric specific data, first line options for empiric anti-fungal therapy in critically ill pediatric patients with neutropenia include liposomal amphotericin B or an echinocandin [48, 69, 87]. Liposomal amphotericin $\mathrm{B}$ has been shown to be associated with fewer breakthrough fungal infections and less toxicity than amphotericin B deoxycholate and is therefore preferred over amphotericin B deoxycholate [88, 89]. Caspofungin has been compared with liposomal amphotericin B as empirical antifungal therapy and was demonstrated to be non-inferior and associated with fewer adverse medication effects in a large adult trial [90]. A smaller pediatric trial comparing these two agents also showed similar efficacy, but no increase in adverse medication events associated with amphotericin B (Table 2) [91]. In a non-inferiority trial comparing liposomal amphotericin B with voriconazole in adult neutropenic patients, voriconazole was associated with fewer breakthrough fungal infections, infusion related toxicity, and nephrotoxicity [92]. Although not studied specifically in children, these adult data suggest that voriconazole may be a reasonable option for empiric antifungal therapy for patients over 2 yr of age and especially in patients with concern for possible Aspergillus infection.

The rationale for recommending antifungal agents that have anti-yeast and anti-mold activity for empiric therapy in a neutropenic patient is that these patients are at higher risk for mold pathogens and also for fluconazole non-susceptible Candida species $(C$. krusei and C. glabrata) $[50,69,93]$. That said, invasive mold infections, including Aspergillus species, mucormycosis, and Fusarium are very rare absent pro- longed ( $>10-15$ days), profound neutropenia (absolute neutrophil count $<100)[94,95]$.

\subsubsection{Non-neutropenic patients}

Though many risk factors for IC have been identified and attempts made to define clinical prediction rules, criteria for initiating empiric antifungal therapy in non-neutropenic patients remain poorly defined, as discussed above. When fever $>4$ days despite broad spectrum antibiotics was used as the criterion to initiate empiric anti-fungal therapy in a cohort of critically ill but not neutropenic adult ICU patients, no difference in outcome was observed between treated and untreated patients [96]. There are no pediatric data on which to base a recommendation for empiric therapy in non-neutropenic patients (Table 2) [69].

\subsection{Preemptive therapy}

Given the costs, toxicities, and potential development of resistant organisms from overuse of antifungal agents with an empiric approach, pre-emptive strategies have been explored in the adult neutropenic patient population. A pre-emptive strategy leverages additional testing modalities like computerized tomography scan or serological markers including Aspergillus galactomannan or $(1 \rightarrow 3) \quad \beta$-D-glucan which can suggest presence of an IFI, absent a positive culture $[49,69,85,97]$. If these testing modalities are consistent with the presence of an IFI then an antifungal agent is initiated. If the testing results are negative then antifungal therapy is not started. In neutropenic adult patients, a pre-emptive antifungal therapy approach has not been associated with higher mortality and is considered a reasonable alternative to empiric therapy by several international guidelines [48, 49, 98, 99]. However, this approach is often focused on invasive Aspergillus infections with limited data for invasive candidal infections and no data that are specific to children. In non-neutropenic ICU patients, there are no studies investigating a pre-emptive approach.

\subsection{Definitive therapy}

\subsubsection{Choice of antifungal agent}

Definitive therapy refers to the targeted treatment of a confirmed invasive candidal infection. Current IDSA guidelines recommend initial therapy with an echinocandin such as caspofungin or micafungin in moderate to severely ill patients, patients with recent 
azole exposure (given increased risk of fluconazole resistant $C$. glabrata and $C$. krusei), and neutropenic patients pending species identification $[50,93]$. Compared with amphotericin $\mathrm{B}$, both caspofungin and micafungin are similarly effective but associated with less toxicity, making them preferred therapy for most patients [27, 50, 69, 100-103]. Anidulafungin has not been compared to amphotericin B, but it was found to be superior to fluconazole for patients with candidemia [104, 105]. Though in the current IDSA guidelines fluconazole is still recommended for less severely ill patients without recent azole exposure, current ESCMID guidelines recommend an echinocandin as first line therapy for all patients based on these data $[50,69,85]$. Micafungin and caspofungin have well documented pharmacokinetic and safety profiles in pediatrics, but anidulafungin is not yet labeled for pediatric usage [100, 106, 107]. There has not been a direct comparison of the echinocandins for treatment of candidiasis but most experts consider them equally effective. Amphotericin B is an alternative therapy (Table 2) [50, 69, 108].

As many patients are started on either an echinocandin or amphotericin B product for initial definitive therapy, there is significant interest in defining the appropriateness of step-down therapy to fluconazole when these patients are improved to complete the course of antifungal therapy [50, 69, 109]. There are limited comparative data documenting the effectiveness of this approach. However, this approach may be reasonable especially when weighing the risk and benefits of maintaining central venous access to continue intravenous antifungal therapy.

\subsubsection{Evaluation for dissemination}

Hematogenous dissemination of Candida to various organs, including lungs, heart, liver, spleen, kidneys, skin, bones, and eyes is possible and often warrants a longer duration of therapy than would be given for isolated candidemia. In a recent large series of pediatric patients, evidence of disseminated disease was identified in $17 \%$ of patients with lung being the most common site $(58 \%)$, followed by liver $(23 \%)$, kidney $(16 \%)$, brain $(12 \%)$, spleen $(8 \%)$, eye $(8 \%)$ and heart $(8 \%)$ [52]. Risk factors for disseminated disease include immunosuppression (neutropenia, bone marrow transplant, or immunosuppressive medications) as well as persistently positive blood cultures (>3 days) with CVC left in place [52]. Evaluation for disseminated disease should include a dilated eye examination for all candidemic patients; this exam should be performed after candidemia has cleared but prior to stopping therapy. Frequency of ocular candidiasis varies from $0-8 \%$ in pediatric case series. This complication can be sight threatening, underscoring the importance of a dilated eye exam in all patients with candidemia [50, 52, 110-112]. Though there are no definitive recommendations regarding evaluation for dissemination to other body sites, abdominal and chest imaging, echocardiography, and focused imaging of painful bones or joints should be considered as clinically indicated [50, 69]. In addition to acute dissemination, neutropenic patients are also at risk for chronic disseminated candidiasis, characterized by fungal microabscess formation in the liver and spleen and often manifest by persistent fevers absent positive blood cultures. Abdominal imaging is required to diagnose this entity [113].

\subsubsection{Duration of definitive therapy}

If there is no evidence of dissemination, candidemia is treated for a total of 14 days from first negative blood culture or from catheter removal. The ultimate duration of therapy for disseminated disease is tailored to the individual patient and is based on clinical response, duration of chemotherapy or other immune suppression, and results of follow-up imaging or examination $[50,69]$. Pharmacokinetic properties should be considered when choosing an antifungal agent in patients with dissemination as penetration of each antifungal agent into specific viscera varies [114]. Additional research is needed to define the most ideal therapeutic approach for disseminated disease.

\subsubsection{Management of central venous catheters}

The management of CVC's in candidemic patients is complex and warrants careful consideration of the potential role of the catheter in the pathogenesis of the infection as well as the risks of catheter removal and replacement for the individual patient. Traditionally, removal of CVC's in cases of candidemia has been recommended based on several non-randomized, primarily adult studies showing an increased risk of prolonged candidemia or death with retained catheters [25, 50, 69, 103, 115-126], though not all studies have confirmed these findings [127-130]. While it is reasonable to recommend line removal based on these prior publications, interpretation of these data must be done with an understanding of the potential for confounding by indication. Specifically, there is a tendency 
to leave CVC's in place in more severely ill patients, who are already at higher risk of mortality, given likely more limited venous access points, morbidity associated with line replacement, or thrombocytopenia or coagulopathy limiting ability to perform procedures [119, 121, 127, 130]. Furthermore, these severely ill patients may die prior to diagnosis of candidemia or opportunity for line removal, introducing a bias towards worse outcomes with catheter retention. When patients who died within $72 \mathrm{hr}$ of positive blood culture are removed from the analysis in one study, the effect of catheter removal on mortality was eliminated [126]. Lastly, not all episodes of candidemia are catheter associated, especially in neutropenic patients where poor gastrointestinal mucosal integrity may predispose this population to more frequent non-catheter associated candidemia than their non-neutropenic counterparts. In such a scenario, catheter removal is likely of less benefit $[116,120]$.

\section{Conclusion and future directions}

Candida species are a frequent cause of invasive infection among medically complex children with medical devices in the PICU resulting in significant morbidity, mortality, and healthcare costs. There has been an increased focus on adult and pediatric candidal infections in the medical literature in the past two decades resulting in better evidence to guide clinical decisions. However, many questions still remain. Future pediatric investigations should focus on better defining the utility of existing biomarkers, improving prediction models to inform the utilization of prophylactic, empiric, or pre-emptive therapies and to define optimal treatment regimens especially for patients with disseminated disease.

\section{References}

[1] Brissaud O, Guichoux J, Harambat J, Tandonnet O, Zaoutis T. Invasive fungal disease in PICU: epidemiology and risk factors. Ann Intensive Care 2012;2(1):6.

[2] Richards MJ, Edwards JR, Culver DH, Gaynes RP. Nosocomial infections in pediatric intensive care units in the United States. National Nosocomial Infections Surveillance System. Pediatrics 1999;103(4):e39.

[3] Grisaru-Soen G, Sweed Y, Lerner-Geva L, Hirsh-Yechezkel G, Boyko V, Vardi A, et al. Nosocomial bloodstream infections in a pediatric intensive care unit: 3-year survey. Med Sci Monit 2007;13(6):Cr251-7.
[4] Tragiannidis A, Fegeler W, Rellensmann G, Debus V, Muller V, Hoernig-Franz I, et al. Candidaemia in a European Paediatric University Hospital: A 10-year observational study. Clin Microbiol Infec 2012;18(2):E27-30.

[5] Watson RS, Carcillo JA, Linde-Zwirble WT, Clermont G, Lidicker J, Angus DC. The epidemiology of severe sepsis in children in the United States. Am J Respir Crit Care Med 2003;167(5):695-701.

[6] Hartman ME, Linde-Zwirble WT, Angus DC, Watson RS Trends in the epidemiology of pediatric severe sepsis. Pediatr Crit Care Med 2013;14(7):686-93.

[7] Pfaller MA, Diekema DJ. Epidemiology of invasive candidiasis: A persistent public health problem. Clin Microbiol Rev 2007;20(1):133-63.

[8] McNeil MM, Nash SL, Hajjeh RA, Phelan MA, Conn LA, Plikaytis BD, et al. Trends in mortality due to invasive mycotic diseases in the United States, 1980-1997. Clin Infect Dis 2001;33(5):641-7.

[9] Dutta A, Palazzi DL. Candida non-albicans versus Candida albicans fungemia in the non-neonatal pediatric population. Pediatr Infect Dis J 2011;30(8):664-8.

[10] Neu N, Malik M, Lunding A, Whittier S, Alba L, Kubin C, et al. Epidemiology of candidemia at a Children's hospital, 2002 to 2006. Pediatr Infect Dis J 2009;28(9):806-9.

[11] Fisher BT, Ross RK, Localio AR, Prasad PA, Zaoutis TE. Decreasing rates of invasive candidiasis in pediatric hospitals across the United States. Clin Infect Dis 2014;58(1):74-7.

[12] Ota KV, McGowan KL. Declining incidence of candidemia in a tertiary inpatient pediatric population. J Clin Microbiol 2012;50(3):1048-50.

[13] Cleveland AA, Farley MM, Harrison LH, Stein B, Hollick R Lockhart SR, et al. Changes in incidence and antifungal drug resistance in candidemia: Results from populationbased laboratory surveillance in Atlanta and Baltimore, 2008-2011. Clin Infect Dis 2012;55(10):1352-61.

[14] Vital signs: Central line-associated blood stream infectionsUnited States, 2001, 2008, and 2009. MMWR Morb Mortal Wkly Rep 2011;60(8):243-8.

[15] Blyth CC, Chen SC, Slavin MA, Serena C, Nguyen Q, Marriott D, et al. Not just little adults: Candidemia epidemiology, molecular characterization, and antifungal susceptibility in neonatal and pediatric patients. Pediatrics 2009;123(5):1360-8.

[16] Wu Z, Liu Y, Feng X, Liu Y, Wang S, Zhu X, et al. Candidemia: Incidence rates, type of species, and risk factors at a tertiary care academic hospital in China. Int J of Infect Dis 2014;22:4-8.

[17] Posfay-Barbe KM, Zerr DM, Pittet D. Infection control in paediatrics. Lancet Infect Dis 2008;8(1):19-31.

[18] Sievert DM, Ricks P, Edwards JR, Schneider A, Patel J Srinivasan A, et al. Antimicrobial-resistant pathogens associated with healthcare-associated infections: Summary of data reported to the National Healthcare Safety Network at the Centers for Disease Control and Prevention, 2009-2010. Infect Control Hosp Epidemiol 2013;34(1):1-14.

[19] Wisplinghoff H, Seifert H, Tallent SM, Bischoff T, Wenzel RP, Edmond MB. Nosocomial bloodstream infections in pediatric patients in the United States hospitals: Epidemiology, clinical features and susceptibilities. Pediatr Infect Dis J 2003;22:686-91

[20] Pfaller MA, Moet GJ, Messer SA, Jones RN, Castanheira M. Candida bloodstream infections: Comparison of 
species distributions and antifungal resistance patterns in community-onset and nosocomial isolates in the SENTRY Antimicrobial Surveillance Program, 2008-2009. Antimicrob Agents Chemother 2011;55(2):561-6

[21] Jordan I, Balaguer M, Lopez-Castilla JD, Belda S, Shuffelman C, Garcia-Teresa MA, et al; ERICAP Study Group. Per-species risk factors and predictors of invasive candida infections in patients admitted to pediatric intensive care units: Development of ERICAP scoring systems. Pediatr Infect Dis J 2014;33(8):e187-93.

[22] Zaoutis TE, Argon J, Chu J, Berlin JA, Walsh TJ, Feudtner C. The Epidemiology and Attributable Outcomes of Candidemia in Adults and Children Hospitalized in the United States: A Propensity Analysis. Clin Infect Dis 2005;41(9):1232-9.

[23] Pappas PG, Rex JH, Lee J, Hamill RJ, Larsen RA, Powderly W, et al. A prospective observational study of candidemia: Epidemiology, therapy, and influences on mortality in hospitalized adult and pediatric patients. Clin Infect Dis 2003;37(5):634-43

[24] Steinbach WJ, Roilides E, Berman D, Hoffman JA, Groll AH, Bin-Hussain I, et al. Results from a prospective, international, epidemiologic study of invasive candidiasis in children and neonates. Pediatr Infect Dis J 2012;31(12):1252-7.

[25] Pasqualotto AC, de Moraes AB, Zanini RR, Severo LC. Analysis of independent risk factors for death among pediatric patients with candidemia and a central venous catheter in place. Infect Control Hosp Epidemiol 2007;28(7): 799-804.

[26] Roilides E, Kadiltsoglou I, Zahides D, Bibashi E. Invasive candidosis in pediatric patients. Clin Microbiol Infect 1997;3(2):192-7.

[27] Palazzi DL, Arrieta A, Castagnola E, Halasa N, Hubbard S, Brozovich AA, et al. Candida speciation, antifungal treatment, and adverse events in pediatric invasive candidiasis: Results from 441 infections in a prospective, multi-national study. Pediatr Infect Dis J 2014 33(12):1294-6.

[28] Pfaller M, Neofytos D, Diekema D, Azie N, Meier-Kriesche HU, Quan SP, et al. Epidemiology and outcomes of candidemia in 3648 patients: Data from the Prospective Antifungal Therapy (PATH Alliance) registry, 2004-2008. Diagn Microbiol Infect Dis 2012;74(4):323-31.

[29] Pfaller MA, Castanheira M, Messer SA, Moet GJ, Jones $\mathrm{RN}$. Variation in Candida spp. distribution and antifungal resistance rates among bloodstream infection isolates by patient age: Report from the SENTRY Antimicrobial Surveillance Program (2008-2009). Diagn Microbiol Infect Dis 2010;68(3):278-83.

[30] Belet N, Ciftci E, Aysev D, Guriz H, Uysal Z, Tacyildiz N, et al. Invasive Candida infections in children: The clinical characteristics and species distribution and antifungal susceptibility of Candida spp. Turk J Pediatr 2011;53:489-98.

[31] Agin H, Devrim I, Isguder R, Karaarslan U, Kanik E, Gunay I, et al. Risk factors for candidemia in pediatric intensive care unit patients. Indian J Pediatr 2014;81(11):1158-62.

[32] Jordan I, Hernandez L, Balaguer M, Lopez-Castilla JD, Casanueva L, Shuffelman C, et al. C. albicans, C. parapsilosis and C. tropicalis invasive infections in the PICU: Clinical features, prognosis and mortality. Rev Esp Quimioter 2014;27(1):56-62.

[33] Pfaller MA, Messer SA, Hollis RJ, Boyken L, Tendolkar S, Kroeger J, et al. Variation in susceptibility of bloodstream isolates of Candida glabrata to fluconazole according to patient age and geographic location in the United States in 2001 to 2007. J Clin Microbiol 2009;47(10):3185-90.

[34] Garey KW, Rege M, Pai MP, Mingo DE, Suda KJ, Turpin RS, et al. Time to initiation of fluconazole therapy impacts mortality in patients with candidemia: A multi-institutional study. Clin Infect Dis 2006;43(1):25-31.

[35] Morrell M, Fraser VJ, Kollef MH. Delaying the empiric treatment of candida bloodstream infection until positive blood culture results are obtained: A potential risk factor for hospital mortality. Antimicrob Agents Chemother 2005;49(9):3640-5

[36] Parkins MD, Sabuda DM, Elsayed S, Laupland KB. Adequacy of empirical antifungal therapy and effect on outcome among patients with invasive Candida species infections. J Antimicrob Chemother 2007;60(3):613-8.

[37] Clancy CJ, Nguyen MH. Finding the "missing 50\%" of invasive candidiasis: How nonculture diagnostics will improve understanding of disease spectrum and transform patient care. Clin Infect Dis 2013;56(9):1284-92.

[38] Lai CC, Wang CY, Liu WL, Huang YT, Hsueh PR. Time to positivity of blood cultures of different Candida species causing fungaemia. J Med Microbiol 2012;61(Pt 5):701-4.

[39] Mikulska M, Calandra T, Sanguinetti M, Poulain D, Viscoli C. The use of mannan antigen and anti-mannan antibodies in the diagnosis of invasive candidiasis: Recommendations from the Third European Conference on Infections in Leukemia. Crit Care 2010;14(6):R222.

[40] Mokaddas E, Burhamah MH, Khan ZU, Ahmad S. Levels of (1->3)-beta-D-glucan, Candida mannan and Candida DNA in serum samples of pediatric cancer patients colonized with Candida species. BMC Infect Dis 2010;10:292.

[41] Mularoni A, Furfaro E, Faraci M, Franceschi A, Mezzano P, Bandettini R, et al. High Levels of beta-D-glucan in immunocompromised children with proven invasive fungal disease. Clin Vaccine Immunol 2010;17(5):882-3.

[42] Smith PB, Benjamin DK, Jr., Alexander BD, Johnson MD, Finkelman MA, Steinbach WJ. Quantification of 1,3-betaD-glucan levels in children: Preliminary data for diagnostic use of the beta-glucan assay in a pediatric setting. Clin Vaccine Immunol 2007;14(7):924-5.

[43] Ostrosky-Zeichner L, Alexander BD, Kett DH, Vazquez J, Pappas PG, Saeki F, et al. Multicenter clinical evaluation of the $(1->3)$ beta-D-glucan assay as an aid to diagnosis of fungal infections in humans. Clin Infect Dis 2005;41(5): 654-9.

[44] Lunel FM, Donnelly JP, van der Lee HA, Blijlevens NM, Verweij PE. Performance of the new Platelia Candida Plus assays for the diagnosis of invasive Candida infection in patients undergoing myeloablative therapy. Med Mycol 2011;49(8):848-55

[45] Odabasi Z, Mattiuzzi G, Estey E, Kantarjian H, Saeki F, Ridge RJ, et al. Beta-D-glucan as a diagnostic adjunct for invasive fungal infections: Validation, cutoff development, and performance in patients with acute myelogenous leukemia and myelodysplastic syndrome. Clin Infect Dis 2004;39(2):199-205.

[46] Montagna MT, Coretti C, Lovero G, De Giglio O, Montagna O, Laforgia N, et al. Diagnostic performance of 1->3-beta-d-glucan in neonatal and pediatric patients with candidemia. Int J Mol Sci 2011;12(9):5871-7.

[47] Goudjil S, Kongolo G, Dusol L, Imestouren F, Cornu M, Leke A, et al. (1-3)-beta-D-glucan levels in candidiasis 
infections in the critically ill neonate. J Matern Fetal Neonatal Med 2013;26(1):44-8.

[48] Groll AH, Castagnola E, Cesaro S, Dalle J-H, Engelhard D, Hope W, et al. Fourth European Conference on Infections in Leukaemia (ECIL-4): Guidelines for diagnosis, prevention, and treatment of invasive fungal diseases in paediatric patients with cancer or allogeneic haemopoietic stem-cell transplantation. Lancet Oncol 2014;15(8):e327-e40.

[49] Freifeld AG, Bow EJ, Sepkowitz KA, Boeckh MJ, Ito JI, Mullen CA, et al. Clinical practice guideline for the use of antimicrobial agents in neutropenic patients with cancer: 2010 update by the Infectious Diseases Society of America. Clin Infect Dis 2011;52(4):427-31.

[50] Pappas PG, Kauffman CA, Andes D, Benjamin DK, Jr., Calandra TF, Edwards JE, Jr., et al. Clinical practice guidelines for the management of candidiasis: 2009 update by the Infectious Diseases Society of America. Clin Infect Dis 2009;48(5):503-35.

[51] Zaoutis TE, Prasad PA, Localio AR, Coffin SE, Bell LM, Walsh TJ, et al. Risk factors and predictors for candidemia in pediatric intensive care unit patients: Implications for prevention. Clin Infect Dis 2010;51(5):e38-45.

[52] Zaoutis TE, Greves HM, Lautenbach E, Bilker WB, Coffin SE. Risk Factors for Disseminated Candidiasis in Children with Candidemia. Pediatr Infect Dis J 2004;23(7):635-41.

[53] Filioti J, Spiroglou K, Panteliadis CP, Roilides E. Invasive candidiasis in pediatric intensive care patients: Epidemiology, risk factors, management, and outcome. Intensive Care Med 2007;33(7):1272-83.

[54] Singhi S, Deep A. Invasive candidiasis in pediatric intensive care units. Indian J Pediatr 2009;76(10):1033-44.

[55] Dotis J, Prasad PA, Zaoutis T, Roilides E. Epidemiology, risk factors and outcome of Candida parapsilosis bloodstream infection in children. Pediatr Infect Dis J 2012;31(6):557-60.

[56] MacDonald L, Baker C, Chenoweth C. Risk factors for candidemia in a children's hospital. Clin Infect Dis 1998;26(3):642-5.

[57] Singhi S, Rao DS, Chakrabarti A. Candida colonization and candidemia in a pediatric intensive care unit. Pediatr Crit Care Med 2008;9(1):91-5.

[58] Pittet D, Monod M, Suter PM, Frenk E, Auckenthaler R. Candida colonization and subsequent infections in critically ill surgical patients. Ann Surg 1994;220(6):751-8.

[59] Leon C, Ruiz-Santana S, Saavedra P, Almirante B, NollaSalas J, Alvarez-Lerma F, et al. A bedside scoring system ("Candida score") for early antifungal treatment in nonneutropenic critically ill patients with Candida colonization. Crit Care Med 2006;34(3):730-7.

[60] Leon C, Ruiz-Santana S, Saavedra P, Galvan B, Blanco A, Castro C, et al. Usefulness of the "Candida score" for discriminating between Candida colonization and invasive candidiasis in non-neutropenic critically ill patients: A prospective multicenter study. Crit Care Med 2009;37(5):1624-33.

[61] Ostrosky-Zeichner L, Sable C, Sobel J, Alexander BD, Donowitz G, Kan V, et al. Multicenter retrospective development and validation of a clinical prediction rule for nosocomial invasive candidiasis in the intensive care setting. Eur J Clin Microbiol Infect Dis 2007;26(4):271-6.

[62] Ostrosky-Zeichner L, Pappas PG, Shoham S, Reboli A, Barron MA, Sims C, et al. Improvement of a clinical prediction rule for clinical trials on prophylaxis for invasive candidiasis in the intensive care unit. Mycoses 2011;54(1):46-51.

[63] Dupont H, Bourichon A, Paugam-Burtz C, Mantz J, Desmonts JM. Can yeast isolation in peritoneal fluid be predicted in intensive care unit patients with peritonitis? Crit Care Med 2003;31(3):752-7.

[64] Robenshtok E, Gafter-Gvili A, Goldberg E, Weinberger M, Yeshurun M, Leibovici L, et al. Antifungal prophylaxis in cancer patients after chemotherapy or hematopoietic stemcell transplantation: Systematic review and meta-analysis. J Clin Oncol 2007;25(34):5471-89.

[65] Rotstein C, Bow EJ, Laverdiere M, Ioannou S, Carr D, Moghaddam N. Randomized placebo-controlled trial of fluconazole prophylaxis for neutropenic cancer patients: Benefit based on purpose and intensity of cytotoxic therapy. The Canadian Fluconazole Prophylaxis Study Group. Clin Infect Dis 1999;28(2):331-40.

[66] Bow EJ, Laverdiere M, Lussier N, Rotstein C, Cheang MS, Ioannou S. Antifungal prophylaxis for severely neutropenic chemotherapy recipients: A meta analysis of randomizedcontrolled clinical trials. Cancer 2002;94(12):3230-46.

[67] Kaufman D, Boyle R, Hazen KC, Patrie JT, Robinson M, Donowitz LG. Fluconazole prophylaxis against fungal colonization and infection in preterm infants. N Engl J Med 2001;345(23):1660-6.

[68] Healy CM, Campbell JR, Zaccaria E, Baker CJ. Fluconazole prophylaxis in extremely low birth weight neonates reduces invasive candidiasis mortality rates without emergence of fluconazole-resistant Candida species. Pediatrics 2008;121(4):703-10.

[69] Hope WW, Castagnola E, Groll AH, Roilides E, Akova M, Arendrup MC, et al. ESCMID guideline for the diagnosis and management of Candida diseases 2012: Prevention and management of invasive infections in neonates and children caused by Candida spp. Clin Microbiol Infect 2012;18 Suppl 7:38-52.

[70] Manzoni P, Stolfi I, Pugni L, Decembrino L, Magnani C, Vetrano G, et al. A multicenter, randomized trial of prophylactic fluconazole in preterm neonates. N Engl J Med 2007;356(24):2483-95.

[71] Benjamin DK, Jr., Hudak ML, Duara S, Randolph DA, Bidegain M, Mundakel GT, et al. Effect of fluconazole prophylaxis on candidiasis and mortality in premature infants: A randomized clinical trial. JAMA 2014;311(17):1742-9.

[72] Rex JH, Sobel JD. Prophylactic antifungal therapy in the intensive care unit. Clin Infect Dis 2001;32(8):1191-200.

[73] Playford EG, Webster AC, Sorrell TC, Craig JC. Antifungal agents for preventing fungal infections in non-neutropenic critically ill patients. Cochrane Database Syst Rev 2006(1):Cd004920.

[74] Vardakas KZ, Samonis G, Michalopoulos A, Soteriades ES, Falagas ME. Antifungal prophylaxis with azoles in highrisk, surgical intensive care unit patients: A meta-analysis of randomized, placebo-controlled trials. Crit Care Med 2006;34(4):1216-24.

[75] Cruciani M, Mengoli C, Malena M, Bosco O, Serpelloni G, Grossi P. Antifungal prophylaxis in liver transplant patients: A systematic review and meta-analysis. Liver Transpl 2006;12(5):850-8.

[76] Playford EG, Webster AC, Sorell TC, Craig JC. Antifungal agents for preventing fungal infections in solid 
organ transplant recipients. Cochrane Database Syst Rev 2004(3):Cd004291

[77] Winston DJ, Pakrasi A, Busuttil RW. Prophylactic fluconazole in liver transplant recipients. A randomized, double-blind, placebo-controlled trial. Ann Intern Med 1999;131(10):729-37.

[78] Pelz RK, Hendrix CW, Swoboda SM, Diener-West M, Merz WG, Hammond J, et al. Double-blind placebo-controlled trial of fluconazole to prevent candidal infections in critically ill surgical patients. Ann Surg 2001;233(4):542-8.

[79] Garbino J, Lew DP, Romand JA, Hugonnet S, Auckenthaler R, Pittet D. Prevention of severe Candida infections in nonneutropenic, high-risk, critically ill patients: A randomized, double-blind, placebo-controlled trial in patients treated by selective digestive decontamination. Intensive Care Med 2002;28(12):1708-17.

[80] Eggimann P, Francioli P, Bille J, Schneider R, Wu MM, Chapuis G, et al. Fluconazole prophylaxis prevents intraabdominal candidiasis in high-risk surgical patients. Crit Care Med 1999;27(6):1066-72.

[81] Piarroux R, Grenouillet Fdr, Balvay P, Tran Vr, Blasco G, Millon L, et al. Assessment of preemptive treatment to prevent severe candidiasis in critically ill surgical patients. Crit Care Med 2004;32(12):2443-9.

[82] Shorr AF, Chung K, Jackson WL, Waterman PE, Kollef MH. Fluconazole prophylaxis in critically ill surgical patients: A meta-analysis. Crit Care Med 2005;33(9):1928-35.

[83] Cruciani M, de Lalla F, Mengoli C. Prophylaxis of Candida infections in adult trauma and surgical intensive care patients: A systematic review and meta-analysis. Intensive Care Med 2005;31(11):1479-87

[84] Ben-Ari J, Samra Z, Nahum E, Levy I, Ashkenazi S, Schonfeld TM. Oral amphotericin B for the prevention of Candida bloodstream infection in critically ill children. Pediatr Crit Care Med 2006;7(2):115-8.

[85] Cornely OA, Bassetti M, Calandra T, Garbino J, Kullberg BJ, Lortholary O, et al. ESCMID guideline for the diagnosis and management of Candida diseases 2012: Non-neutropenic adult patients. Clin Microbiol Infect 2012;18(Suppl 7):1937.

[86] Ostrosky-Zeichner L, Shoham S, Vazquez J, Reboli A, Betts R, Barron MA, et al. MSG-01: A randomized, doubleblind, placebo-controlled trial of caspofungin prophylaxis followed by preemptive therapy for invasive candidiasis in high-risk adults in the critical care setting. Clin Infect Dis 2014;58(9):1219-26.

[87] Lehrnbecher T, Phillips R, Alexander S, Alvaro F, Carlesse F, Fisher B, et al. Guideline for the management of fever and neutropenia in children with cancer and/or undergoing hematopoietic stem-cell transplantation. J Clin Oncol 2012;30(35):4427-38.

[88] Walsh TJ, Finberg RW, Arndt C, Hiemenz J, Schwartz C, Bodensteiner D, et al. Liposomal amphotericin B for empirical therapy in patients with persistent fever and neutropenia. National Institute of Allergy and Infectious Diseases Mycoses Study Group. New Engl J Med 1999;340(10):764-71.

[89] Prentice HG, Hann IM, Herbrecht R, Aoun M, Kvaloy S, Catovsky D, et al. A randomized comparison of liposomal versus conventional amphotericin B for the treatment of pyrexia of unknown origin in neutropenic patients. $\mathrm{Br} \mathrm{J}$ Haematol 1997;98(3):711-8.
[90] Walsh TJ, Teppler H, Donowitz GR, Maertens JA, Baden LR, Dmoszynska A, et al. Caspofungin versus liposomal amphotericin B for empirical antifungal therapy in patients with persistent fever and neutropenia. New Engl J Med 2004;351(14):1391-402.

[91] Maertens JA, Madero L, Reilly AF, Lehrnbecher T, Groll AH, Jafri HS, et al. A randomized, double-blind, multicenter study of caspofungin versus liposomal amphotericin $\mathrm{B}$ for empiric antifungal therapy in pediatric patients with persistent fever and neutropenia. Pediatric Infect Dis $\mathbf{J}$ 2010;29(5):415-20.

[92] Walsh TJ, Pappas P, Winston DJ, Lazarus HM, Petersen F, Raffalli J, et al. Voriconazole compared with liposomal amphotericin B for empirical antifungal therapy in patients with neutropenia and persistent fever. New Engl J Med 2002;346(4):225-34

[93] Prasad PA, Fisher BT, Coffin SE, Walsh TJ, McGowan KL, Gross R, et al. Pediatric risk factors for Candidemia secondary to Candida glabrata and Candida krusei species. J Pediatric Infect Dis Soc 2013;2(3):263-6.

[94] Cornillet A, Camus C, Nimubona S, Gandemer V, Tattevin $\mathrm{P}$, Belleguic $\mathrm{C}$, et al. Comparison of epidemiological, clinical, and biological features of invasive aspergillosis in neutropenic and nonneutropenic patients: A 6-year survey. Clin Infect Dis 2006;43(5):577-84.

[95] Portugal RD, Garnica M, Nucci M. Index to predict invasive mold infection in high-risk neutropenic patients based on the area over the neutrophil curve. J Clin Oncol 2009;27(23):3849-54.

[96] Schuster MG, Edwards JE, Jr., Sobel JD, Darouiche RO, Karchmer AW, Hadley S, et al. Empirical fluconazole versus placebo for intensive care unit patients: A randomized trial. Ann Intern Med 2008;149(2):83-90.

[97] Segal BH, Almyroudis NG, Battiwalla M, Herbrecht R, Perfect JR, Walsh TJ, et al. Prevention and early treatment of invasive fungal infection in patients with cancer and neutropenia and in stem cell transplant recipients in the era of newer broad-spectrum antifungal agents and diagnostic adjuncts. Clin Infect Dis 2007;44(3):402-9.

[98] Tan BH, Low JG, Chlebicka NL, Kurup A, Cheah FK, Lin RT, et al. Galactomannan-guided preemptive vs. empirical antifungals in the persistently febrile neutropenic patient: A prospective randomized study. Int $\mathbf{J}$ Infect Dis 2011;15(5):e350-6.

[99] Cordonnier C, Pautas C, Maury S, Vekhoff A, Farhat H, Suarez F, et al. Empirical versus preemptive antifungal therapy for high-risk, febrile, neutropenic patients: A randomized, controlled trial. Clin Infect Dis 2009;48(8):1042-51.

[100] Mora-Duarte J, Betts R, Rotstein C, Colombo AL, Thompson-Moya L, Smietana J, et al. Comparison of caspofungin and amphotericin B for invasive candidiasis. New Engl J Med 2002;347(25):2020-9.

[101] Kuse E-R, Chetchotisakd P, da Cunha CA, Ruhnke M, Barrios C, Raghunadharao D, et al. Micafungin versus liposomal amphotericin B for candidaemia and invasive candidosis: A phase III randomised double-blind trial. Lancet 2007;369(9572):1519-27

[102] Queiroz-Telles F, Berezin E, Leverger G, Freire A, van der Vyver A, Chotpitayasunondh T, et al. Micafungin versus liposomal amphotericin B for pediatric patients with invasive candidiasis: Substudy of a randomized doubleblind trial. Pediatr Infect Dis J 2008;27(9):820-6. 
[103] Pappas PG, Rotstein CM, Betts RF, Nucci M, Talwar D, De Waele JJ, et al. Micafungin versus caspofungin for treatment of candidemia and other forms of invasive candidiasis. Clin Infect Dis 2007;45(7):883-93.

[104] Reboli AC, Rotstein C, Pappas PG, Chapman SW, Kett DH, Kumar D, et al. Anidulafungin versus fluconazole for invasive candidiasis. New Engl J Med 2007;356(24):2472-82.

[105] Kett DH, Shorr AF, Reboli AC, Reisman AL, Biswas P, Schlamm HT. Anidulafungin compared with fluconazole in severely ill patients with candidemia and other forms of invasive candidiasis: Support for the 2009 IDSA treatment guidelines for candidiasis. Crit Care 2011;15(5):R253.

[106] Walsh TJ, Adamson PC, Seibel NL, Flynn PM, Neely MN, Schwartz C, et al. Pharmacokinetics, safety, and tolerability of caspofungin in children and adolescents. Antimicrob Agents Chemother 2005;49(11):4536-45.

[107] Autmizguine J, Guptill JT, Cohen-Wolkowiez M, Benjamin DK Jr, Capparelli EV. Pharmacokinetics and pharmacodynamics of antifungals in children: Clinical implications. Drugs 2014;74(8):891-909.

[108] Kullberg BJ, Sobel JD, Ruhnke M, Pappas PG, Viscoli $\mathrm{C}$, Rex JH, et al. Voriconazole versus a regimen of amphotericin B followed by fluconazole for candidaemia in non-neutropenic patients: A randomised non-inferiority trial. Lancet 2005;366(9495):1435-42.

[109] Vazquez J, Reboli AC, Pappas PG, Patterson TF, Reinhardt J, Chin-Hong P, et al. Evaluation of an early step-down strategy from intravenous anidulafungin to oral azole therapy for the treatment of candidemia and other forms of invasive candidiasis: Results from an open-label trial. BMC Infect Dis 2014;14:97.

[110] Dozier CC, Tarantola RM, Jiramongkolchai K, Donahue SP. Fungal eye disease at a tertiary care center: The utility of routine inpatient consultation. Ophthalmology 2011;118(8):1671-6.

[111] Donahue SP, Hein E, Sinatra RB. Ocular involvement in children with candidemia. Am J Ophthalmol 2003;135(6):886-7.

[112] Fierro JL, Prasad PA, Fisher BT, Gerber JS, Coffin SE, Walsh TJ, et al. Ocular manifestations of candidemia in children. Pediatr Infect Dis J 2013;32(1):84-6.

[113] Rammaert B, Desjardins A, Lortholary O. New insights into hepatosplenic candidosis, a manifestation of chronic disseminated candidosis. Mycoses 2012;55(3):e74-84.

[114] Felton T, Troke PF, Hope WW. Tissue penetration of antifungal agents. Clin Microbiol Rev 2014;27(1):68-88.

[115] Ellis M, Hedstrom U, Jumaa P, Bener A. Epidemiology, presentation, management and outcome of candidemia in a tertiary care teaching hospital in the United Arab Emirates, 1995-2001. Med Mycol 2003;41(6):521-8.

[116] Garnacho-Montero J, Diaz-Martin A, Garcia-Cabrera E, Ruiz Perez de Pipaon M, Hernandez-Caballero C, LepeJimenez JA. Impact on hospital mortality of catheter removal and adequate antifungal therapy in Candida spp. bloodstream infections. J Antimicrob Chemother 2013;68(1):206-13.
[117] Liu CY, Huang LJ, Wang WS, Chen TL, Yen CC, Yang $\mathrm{MH}$, et al. Candidemia in cancer patients: Impact of early removal of non-tunneled central venous catheters on outcome. J Infect 2009;58(2):154-60.

[118] Nguyen MH, Peacock JE, Jr., Tanner DC, Morris AJ, Nguyen ML, Snydman DR, et al. Therapeutic approaches in patients with candidemia. Evaluation in a multicenter, prospective, observational study. Arch Intern Med 1995;155(22):2429-35.

[119] Puig-Asensio M, Peman J, Zaragoza R, Garnacho-Montero J, Martin-Mazuelos E, Cuenca-Estrella M, et al. Impact of therapeutic strategies on the prognosis of candidemia in the ICU. Crit Care Med 2014;42(6):1423-32.

[120] Raad I, Hanna H, Boktour M, Girgawy E, Danawi H, Mardani M, et al. Management of central venous catheters in patients with cancer and candidemia. Clin Infect Dis 2004;38(8):1119-27.

[121] Rex JH, Bennett JE, Sugar AM, Pappas PG, Serody J, Edwards JE, et al. Intravascular catheter exchange and duration of candidemia. NIAID Mycoses Study Group and the Candidemia Study Group. Clin Infect Dis 1995;21(4):994-6.

[122] Schelenz S, Gransden WR. Candidaemia in a London teaching hospital: Analysis of 128 cases over a 7-year period. Mycoses 2003;46(9-10):390-6.

[123] Weinberger M, Leibovici L, Perez S, Samra Z, Ostfeld I, Levi I, et al. Characteristics of candidaemia with Candidaalbicans compared with non-albicans Candida species and predictors of mortality. J Hosp Infect 2005;61(2):146-54.

[124] Karlowicz MG, Hashimoto LN, Kelly RE, Jr., Buescher ES. Should central venous catheters be removed as soon as candidemia is detected in neonates? Pediatrics 2000;106(5):E63.

[125] Anaissie EJ, Rex JH, Uzun Ö, Vartivarian S. Predictors of adverse outcome in cancer patients with candidemia. Am J Med 1998;104(3):238-45.

[126] Velasco E, Bigni R. A prospective cohort study evaluating the prognostic impact of clinical characteristics and comorbid conditions of hospitalized adult and pediatric cancer patients with candidemia. Eur J Clin Microbiol Infect Dis 2008;27(11):1071-8.

[127] Nucci M, Silveira MI, Spector N, Silveira F, Velasco E, Akiti $\mathrm{T}$, et al. Risk factors for death among cancer patients with fungemia. Clin Infect Dis 1998;27(1):107-11.

[128] Nucci M, Anaissie E, Betts RF, Dupont BF, Wu C, Buell DN, et al. Early removal of central venous catheter in patients with candidemia does not improve outcome: Analysis of 842 patients from 2 randomized clinical trials. Clin Infect Dis 2010;51(3):295-303.

[129] Rodriguez D, Park BJ, Almirante B, Cuenca-Estrella M, Planes AM, Mensa J, et al. Impact of early central venous catheter removal on outcome in patients with candidaemia. Clin Microbiol Infect 2007;13(8):788-93.

[130] Nucci M, Anaissie E. Should vascular catheters be removed from all patients with candidemia? An evidence-based review. Clin Infect Dis 2002;34(5):591-9. 